\title{
AMMONIA-LOWERING STRATEGIES FOR THE TREATMENT OF HEPATIC ENCEPHALOPATHY
}

\section{Christopher F. Rose}

Author affiliations: 1. Neuroscience Research Unit, Hôpital Saint-Luc (CRCHUM), Université de Montréal, Québec, Canada

Corresponding author: Christopher F. Rose Ph.D., Neuroscience Research Unit, Hôpital Saint-Luc (CRCHUM), Université de Montréal, Québec, Canada. Phone: +1 514890 8000, ext. 35739; email: christopher.rose@umontreal.ca

Number of references : 75

Number of figures : 8

Keywords : Brain, Hepatic, Metabolism, Neurological, Therapeutics

\section{ABSTRACT}

Hyperammonemia leads to neurotoxic levels of brain ammonia and is a major factor involved in the pathogenesis of hepatic encephalopathy (HE). Ammonia-lowering treatments primarily involve two strategies: inhibiting ammonia production and/or increasing ammonia removal. Targeting the gut has been the primary focus for many years, with the goal of inhibiting the generation of ammonia. However, in the context of liver failure, extrahepatic organs containing ammonia metabolic pathways have become new potential ammonia-lowering targets. Skeletal muscle has the capacity to remove ammonia by producing glutamine through the enzyme glutamine synthetase (amidation of glutamate) and, given its large mass, has the potential to be an important ammoniaremoving organ. On the other hand, glutamine can be deaminated to glutamate by phosphate-activated glutaminase, thus releasing ammonia (ammonia rebound). Therefore, new treatment strategies are being focused on stimulating the removal of both ammonia and glutamine.

Hepatic encephalopathy (HE) is a common, debilitating, and clinically challenging neuropsychiatric complication of both acute liver failure and chronic liver disease. Characterized by a constellation of symptoms, including a spectrum of cognitive, psychiatric, and motor disturbances, HE can progressively lead to coma and death. In 1998, the working party at the 11th World Congress of Gastroenterology classified HE 
into three types, based on the nature of hepatic dysfunction. Type A HE is associated with acute liver failure; type B occurs with portal-systemic shunting (bypass) without intrinsic liver disease; and type $\mathrm{C}$ develops in patients with cirrhosis (Figure 1). This review focuses on the role of ammonia in the pathogenesis of type $\mathrm{C} \mathrm{HE}$ and describes various ammonia-lowering therapeutic strategies.



Figure 1 Classification and types of hepatic encephalopathy. Based on the underlying cause, hepatic encephalopathy (HE) is divided into three forms: (1) type A, associated with acute liver failure; (2) type B, arising because of portal-systemic shunting in the absence of any intrinsic liver disease; and (3) type $\mathrm{C}$, which develops in patients with cirrhosis. Type C HE can be further divided into (a) overt $\mathrm{HE}$ (OHE), which is diagnosed from obvious clinical signs such as hyperreflexia, rigidity, myoclonus, asterixis, stupor, and seizures, and (b) minimal HE, which is described when no overt or obvious symptoms of HE are observed and is diagnosed using sensitive neuropsychologic and neurophysiologic tests. OHE can then be further subdivided into (i) episodic HE, characterized by bouts of clinically overt symptoms developing over a short period of time, and (ii) persistent HE, characterized by continuous symptoms of OHE.

Cirrhosis-related HE is further classified into two forms: minimal HE (MHE) and overt HE (OHE). In MHE, no overt or obvious manifestations of HE are observed; it is diagnosed using sensitive neuropsychological and neurophysiological tests. ${ }^{-}$MHE is characterized by decreased attention, poor concentration, impaired memory, sleep 
This is the peer reviewed version of the following article: Rose C F. Ammonia-Lowering Strategies for the Treatment of Hepatic Encephalopathy. Clin Pharmacol Ther . 2012-09;92(3):321-331, which has been published in final form at 10.1038/clpt.2012.112. This article may be used for non-commercial purposes in accordance with Wiley Terms and Conditions for Use of Self-Archived Versions.

disturbances, reduced speed of information processing, and altered motor abilities. In addition, the subclinical cognitive impairment that characterizes MHE increases the risk of having a car accident. As such, MHE has a significant impact on patients' healthrelated quality of life and their ability to carry out day-to-day functions. ${ }^{1}$ As many as $80 \%$ (20-80\%, depending on the severity of the disease) of patients with chronic liver disease may have MHE. Its presence also identifies patients with a fourfold higher risk of developing OHE. $\stackrel{2}{ }$

OHE may involve several clinical signs, including hyperreflexia, rigidity, myoclonus, asterixis, stupor, and seizures; the West Haven Criteria are routinely used to grade the severity of manifestations. In addition, based on the duration and characteristics of neurologic dysfunction, OHE can manifest as either episodic or persistent. HE is said to be episodic when bouts of clinically overt symptoms develop over a short period of time, whereas persistent $\mathrm{HE}$ is defined as the continuous presence of symptoms (Figure 1). Patients with persistent $\mathrm{HE}$ are usually unresponsive to treatment. In patients with endstage liver disease, there is a $20 \%$ annual risk of developing an episode of OHE, and the prevalence of OHE among these patients is $30-45 \% . \frac{3}{-}$ The clinical prognosis is poor after OHE has developed, with 1-year survival estimated at $42 \%$ and 3 -year survival at $23 \% .2$ Overall, the burden of HE is immense, considering its wide-ranging effects on patients, their families, and society. The economic drain caused by HE on health-care systems is estimated at more than US\$1 billion annually. With the increasing prevalence of hepatitis $\mathrm{C}$ and nonalcoholic steatohepatitis-related cirrhosis, the situation is expected to worsen. ${ }^{2,4}$

\section{REGULATION OF AMMONIA}

The pathophysiologic basis of HE is multifactorial and complex, and it remains poorly understood. However, there is general consensus that ammonia plays a pivotal role in HE. ${ }^{5}, \underline{6}$ Ammonia, a by-product of nitrogen metabolism, is produced mainly within the gut through the deamination of glutamine by glutaminase in the enterocytes of the small intestine and colon, as well as through the hydrolysis of urea, catalyzed by ureaseproducing bacteria that exist abundantly in the human gut. Gut-derived ammonia is transported and absorbed across the mucosal epithelium into the hepatic portal circulation, from which, in the case of a healthy liver, it is removed primarily through the urea cycle. This low-affinity, high-capacity ammonia detoxification system is present in the periportal hepatocytes located around the portal vein. Glutamine synthetase, another important ammonia-removing pathway located in the liver, catalyzes the amidation of glutamate into glutamine, thereby removing an ammonia molecule. This high-affinity, low-capacity reaction takes place in the perivenous hepatocytes located around the hepatic vein and acts as a scavenger for the ammonia that escapes periportal urea synthesis. The production of ammonia within the gut and its detoxification by the liver are the main pathways through which ammonia homeostasis is maintained in the body. However, other organs also contribute to ammonia metabolism. In addition to the liver 
and intestines, glutamine synthetase is found in the muscles and the brain (particularly in the astrocytes) and in phosphate-activated glutaminase in the kidneys and the brain (primarily in the neurons). In the presence of a healthy liver, blood ammonia levels are maintained in the low range of 35-60 $\mu \mathrm{mol} / \mathrm{l}$ (Figure 2). However, during liver disease, given the reduced hepatic capacity for ammonia removal, the extrahepatic interorgan ammonia metabolism is altered (including glutamine metabolism), ${ }^{7}$ thus upsetting the balance between ammonia-producing/removing organs and ammonia homeostasis (Figure 2). This results in a two- to fivefold increase in blood ammonia, leading to an increase in ammonia levels in the brain, with deleterious consequences. ${ }^{5,6}$

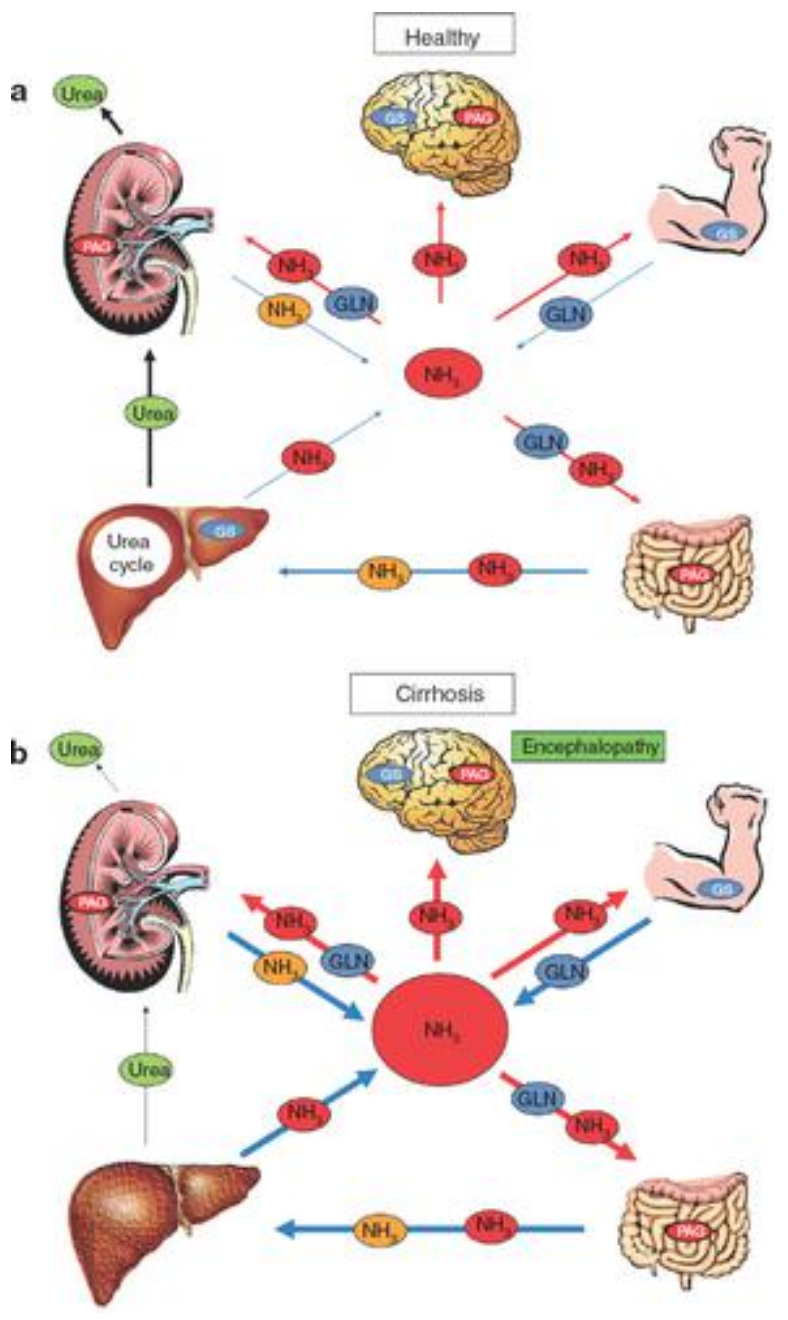

Figure 2 Interorgan ammonia $\left(\mathrm{NH}_{3}\right)$ and glutamine (GLN) trafficking under normal and cirrhotic conditions. Many organs are involved in regulating whole-body ammonia homeostasis. (a) The liver is the most important organ in regulating the circulating concentration of ammonia to remain in the range 35-60 $\mu \mathrm{mol} / \mathrm{l}$. (b) During liver disease, the arterial concentration of ammonia can increase fivefold. This is obviously due to lower ammonia detoxification in the liver (reduced urea-cycle and glutamine synthetase (GS) activity). Furthermore, under these conditions, interorgan metabolism is 
This is the peer reviewed version of the following article: Rose C F. Ammonia-Lowering Strategies for the Treatment of Hepatic Encephalopathy. Clin Pharmacol Ther . 2012-09;92(3):321-331, which has been published in final form at 10.1038/clpt.2012.112. This article may be used for non-commercial purposes in accordance with Wiley Terms and Conditions for Use of Self-Archived Versions.

altered. The muscle becomes the major ammonia-removing organ, through the GS mechanism; however, attempts by the muscle to detoxify ammonia by means of forming and releasing GLN are negated when GLN is metabolized by phosphate-activated glutaminase (PAG) in both the kidney and the intestine. With a net balance of zero ammonia removed, and continuous production of ammonia in the gut (by diet as well as PAG/urease activity), hyperammonemia will persist. For a complete review of interorgan ammonia metabolism in liver disease, please see ref. ${ }^{7}$. Red circles: circulating ammonia; blue circles: circulating GLN; orange circles: GLN-derived ammonia.

\section{PROPERTIES OF AMMONIA}

Ammonia as a gas $\left(\mathrm{NH}_{3}\right)$ can freely diffuse across all cell membranes, and as an ion $\left(\mathrm{NH}_{4}{ }^{+}\right)$it can be transported across plasma membranes through $\mathrm{K}^{+}$transporters and channels because it has properties similar to those of $\mathrm{K}^{+}$(comparable ionic radius and diffusion coefficient). The ratio of $\mathrm{NH}_{3} / \mathrm{NH}_{4}{ }^{+}$is a function of $\mathrm{pH}$ as defined by the Henderson-Hasselbach equation: $\log _{10}\left(\mathrm{NH}_{3} / \mathrm{NH}_{4}{ }^{+}\right)=\mathrm{pH}-\mathrm{p} K_{\mathrm{a}}$, where $\mathrm{p} K_{\mathrm{a}}$ is dissociation constant. With the $\mathrm{p} K_{\mathrm{a}}$ of ammonia being 9.15 (at $37{ }^{\circ} \mathrm{C}$ and $\mathrm{pH} 7.4$ ) $>98 \%$ of ammonia is present as $\mathrm{NH}_{4}{ }^{+}$. There is increasing evidence to indicate that ammonia can also be transported through aquaporin channels, as well as through human nonerythroid Rhesus glycoproteins B and C (Figure 3). It has been proposed that an ammonia concentration gradient exists between the brain and the blood. However, studies in animals with and without liver failure have demonstrated similar concentrations of ammonia in the blood, cerebrospinal fluid, and extracellular fluid (sampled using in vivo cerebral microdialysis), $\stackrel{8,9}{ }$ including a strong correlation between arterial and extracellular cerebral ammonia..$^{10}$ It is understood that a difference in $\mathrm{pH}$ across plasma membranes, i.e., between intracellular and extracellular compartments, will alter the ratio of $\mathrm{NH}_{3} / \mathrm{NH}_{4}{ }^{+}$on either side of the membrane. A pH gradient between blood and brain will create concentration gradients for $\mathrm{NH}_{3}$ and $\mathrm{NH}_{4}{ }^{+}$across the blood-brain barrier. However, given that both $\mathrm{NH}_{3}$ and $\mathrm{NH}_{4}{ }^{+}$are capable of crossing biological membranes $\left(\mathrm{NH}_{3}\right.$ diffuses faster than $\mathrm{NH}_{4}{ }^{+}$is transported), the concentration levels of ammonia $\left(\mathrm{NH}_{3}+\right.$ $\mathrm{NH}_{4}{ }^{+}$) in the blood and in the brain will reach equilibrium and be similar. Nevertheless, it has been demonstrated that an increase in blood ammonia leads to an increase in cerebral uptake; $\underline{-11}$ but this does not necessarily dictate an accumulation of ammonia in the brain, nor does it, therefore, entail a higher concentration in the brain. Given that ammonia follows its concentration gradient, and that astrocytes (which outnumber neurons $\sim 1.5: 1$ ) detoxify ammonia through the synthesis of glutamine by glutamine synthetase, the brain becomes a sink for ammonia. Therefore, the concentration of blood ammonia as well as the efficiency of ammonia removal in the brain will influence its uptake across the bloodbrain barrier. $\underline{12}$ 


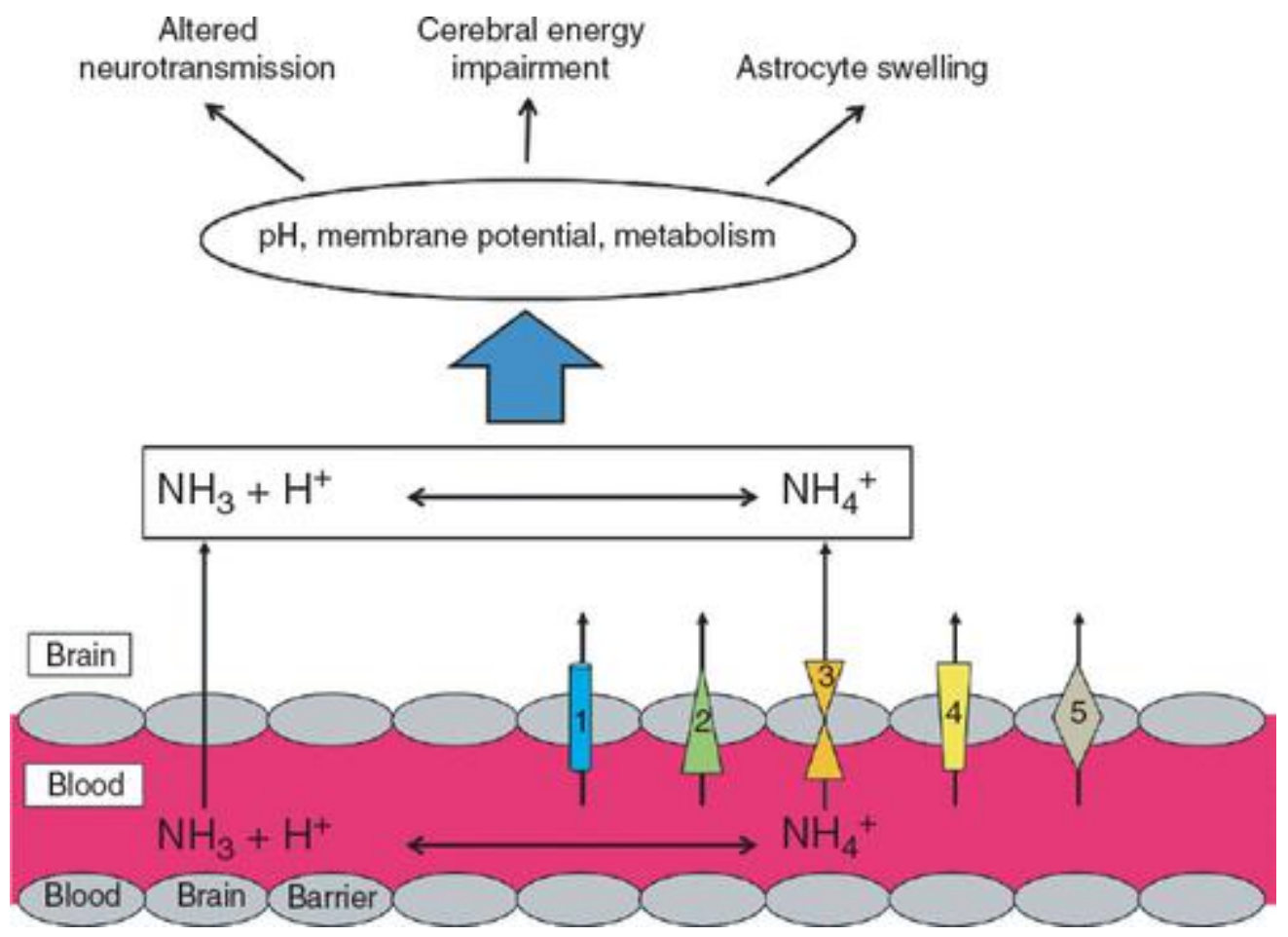

Figure 3 Mechanisms and effects of ammonia uptake into the brain. Ammonia in the form of $\mathrm{NH}_{3}$, being a gas, can diffuse across cell membranes, whereas $\mathrm{NH}_{4}{ }^{+}$is transported across plasma membranes by $\mathrm{K}^{+}$-channels and transporters such as (1) $\mathrm{Na}^{+} / \mathrm{K}^{+}$-ATPase, $\mathrm{Na}^{+} / \mathrm{H}^{+}$-ATPase antiporters, (2) inward rectifying $\mathrm{K}^{+}$-channels (uniporters), (3) $\mathrm{Na}^{+} / \mathrm{K}^{+} / 2 \mathrm{Cl}^{-}, \mathrm{K}^{+} / \mathrm{Cl}^{-}$symporters, (4) ammonia transporters, and (5) aquaporins. An increase in neurotoxic levels of ammonia leads directly to shifts in $\mathrm{pH}$, changes in membrane potential and a compromised metabolism, causing deleterious effects such as astrocyte swelling, energy impairment, and alterations in neurotransmission.

\section{NEUROTOXICITY OF AMMONIA}

HE is often precipitated by ammoniagenic conditions such as the ingestion of a protein load, constipation, or a gastrointestinal bleed, resulting in an elevation of ammonia concentration in the brain. HE then triggers a cascade of metabolic events that are implicated in its development. The neurotoxicity of ammonia is explained by the direct effects of ammonia on $\mathrm{pH}$, membrane potential, and cellular metabolism. ${ }^{5}$ Ammonia $\left(\mathrm{NH}_{4}{ }^{+}\right.$and $\left.\mathrm{NH}_{3}\right)$ can act as a weak base or as a weak acid and is therefore capable of altering the $\mathrm{pH}$ of the environment. ${ }^{13}$ Given that $\mathrm{K}^{+}$and $\mathrm{NH}_{4}{ }^{+}$have comparable properties, an increase in $\mathrm{NH}_{4}{ }^{+}$can lead to a change in resting membrane potential, thereby exerting a direct effect on neurotransmission. ${ }^{5}$ Furthermore, ammonia is an important metabolic end product as well as an intermediate of many different biochemical reactions in the body; therefore, an increase in ammonia will have an impact on cellular metabolism and function as well. These direct effects of ammonia, together or 
This is the peer reviewed version of the following article: Rose C F. Ammonia-Lowering Strategies for the Treatment of Hepatic Encephalopathy. Clin Pharmacol Ther . 2012-09;92(3):321-331, which has been published in final form at 10.1038/clpt.2012.112. This article may be used for non-commercial purposes in accordance with Wiley Terms and Conditions for Use of Self-Archived Versions.

independently, can lead to several pathophysiologic mechanisms that affect cellular functions, including cellular energy metabolism, neurotransmission, and astrocyte swelling $\underline{\text { (Figure } 3}$ ).

\section{NEUROPATHOLOGY}

The neuropathology of HE in chronic liver disease primarily reveals morphological changes in astrocytes, including cell swelling and the development of Alzheimer type II astrocytosis. Loss of neuronal cells is rarely observed in liver disease. Astrocyte swelling, which is responsible for brain edema, is a common feature found in cirrhotic rats with

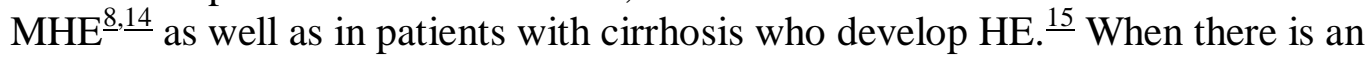
increase in ammonia levels in the brain, it is the astrocyte that bears the brunt of removing ammonia because these glial cells are the only cells in the brain capable of detoxifying ammonia through the synthesis of glutamine by glutamine synthetase. It has been postulated that the accumulation of glutamine in astrocytes, subsequent to ammonia detoxification, results in an increase in osmotic forces, leading to swelling in HE. However, our group and others have demonstrated that glutamine is not the sole factor involved in the pathogenesis of astrocyte swelling, $\frac{16}{}$ and that the precise pathophysiologic mechanisms underlying the development of brain edema in HE remain unexplained. More importantly, given that the swelling of astrocytes not only leads to brain edema but is also capable of compromising cell function, it remains controversial whether brain edema symbolizes a neuropathologic feature of HE, or whether HE is a clinical manifestation of brain edema.

Although there is overwhelming evidence of the central role of ammonia in the pathogenesis of $\mathrm{HE}$, and data show that $80 \%$ of patients with cirrhosis present some degree of hyperammonemia,,$\underline{17}$ it is important to note that many studies have reported an imperfect correlation between hyperammonemia and the severity of HE in chronic liver disease. $\frac{18}{}$ This suggests that pathogenic factors besides ammonia are involved in the pathogenesis of HE. It has been speculated that oxidative stress and inflammation may exacerbate the neuropsychologic effects of hyperammonemia. $\underline{8}, \underline{19}, \underline{20}$ The roles of these pathophysiologic factors in the development of HE are not addressed in this review.

\section{TREATMENTS}

Currently, treatment for HE is based on strategies aimed at reducing the concentration of circulating blood ammonia (Figure 4). One obvious strategy is to address the source of ammonia production, with the gut being a primary target. Reducing ammonia production will minimize its absorption into the systemic circulation and hence the brain's exposure to it. However, because interorgan ammonia metabolism is altered during the onset of liver disease, ${ }^{7}$ additional organs, such as skeletal muscle, become important players in the 
This is the peer reviewed version of the following article: Rose C F. Ammonia-Lowering Strategies for the Treatment of Hepatic Encephalopathy. Clin Pharmacol Ther . 2012-09;92(3):321-331, which has been published in final form at 10.1038/clpt.2012.112. This article may be used for non-commercial purposes in accordance with Wiley Terms and Conditions for Use of Self-Archived Versions.

metabolism of ammonia. Skeletal muscle, which contains the ammonia-removing enzyme glutamine synthetase, makes up $\sim 40 \%$ of total body mass. Therefore, increasing the capacity of skeletal muscle to remove ammonia is a potential approach in the treatment of HE.

Ammonia production $\longrightarrow \begin{gathered}\text { Synergistic } \\ \text { combination }\end{gathered}$
$\begin{array}{ll}\text { Lactulose } & \text { Ammonia removal } \\ \text { Antibiotics } & \text { Branched-chain amino acids } \\ \text { Phenylacetate/phenylbutyrate } & \text { L-ornithine L-aspartate }\end{array}$
AST-120
Benzoate
Glutaminase inhibitors
Acarbose

Figure 4 Ammonia-lowering strategies.

\section{DECREASING AMMONIA PRODUCTION}

Protein restriction. Protein restriction was once a common therapeutic option for cirrhotic patients to prevent a rise in gut-derived blood ammonia. This approach is no longer recommended because it promotes protein degradation, decreases muscle mass, and can cause deterioration in the patient's nutritional status. ${ }^{21}$ The available evidence does not support protein restriction, and proper nutrition is recognized as being a very important element of the management of patients with chronic liver disease. Current dietary recommendations are $35-40 \mathrm{kcal} / \mathrm{kg} /$ day and $1.2-1.5 \mathrm{~g}$ protein $/ \mathrm{kg} / \mathrm{day} .^{21}$

Malnutrition is a common complication of chronic liver disease and is estimated to affect between 25 and $80 \%$ of cirrhotic patients. It increases with the severity of the disease and is an important prognostic indicator of clinical outcome. The liver plays a critical role in maintaining proper nutrition by regulating the traffic of nutrients; during liver disease, this metabolic balance becomes deregulated, causing numerous nutritional and metabolic complications. Several factors contribute to the development of malnutrition in liver disease (for a review, see ref. ${ }^{21}$ ), and malnutrition is associated with an increased prevalence of HE. In addition, $\mathrm{HE}$ is also believed to lead to poor nutritional intake, thus creating a vicious circle. Overall, the role of nutrition as a key component in the pathogenesis of HE has been undervalued.

Nonabsorbable disaccharides. To date, nonabsorbable disaccharides, particularly lactulose, are the first-line therapy for patients with end-stage liver disease and HE. Lactulose is a synthetic disaccharide composed of the monosaccharides fructose and galactose. It remains undigested until it reaches the colon, where it is metabolized by colonic bacteria into acetic acid and lactic acid. These carboxylic acids reduce the intraluminal $\mathrm{pH}$ and the resulting acidification of the colon suppresses the growth of the

Rose C F. Ammonia-Lowering Strategies for the Treatment of Hepatic Encephalopathy. Clin Pharmacol Ther . 201209;92(3):321-331 
This is the peer reviewed version of the following article: Rose C F. Ammonia-Lowering Strategies for the Treatment of Hepatic Encephalopathy. Clin Pharmacol Ther . 2012-09;92(3):321-331, which has been published in final form at 10.1038/clpt.2012.112. This article may be used for non-commercial purposes in accordance with Wiley Terms and Conditions for Use of Self-Archived Versions.

intestinal urease bacteria (ammoniagenic bacteria), leaving acid-resistant, nonammoniagenic bacteria. Lactulose also decreases the absorption of ammonia through a cathartic effect, clearing the gut of ammonia before it is systemically absorbed, resulting in increased fecal nitrogen excretion. Lactulose has also been shown to impede the uptake of glutamine by the intestinal wall, thus preventing glutamine from being metabolized into ammonia. $\frac{22}{}$ As a result, numerous studies have demonstrated that lactulose treatment leads to a reduction in blood ammonia levels. $\frac{23}{}$ However, in 2004, a Cochrane review evaluating 22 clinical trials concluded that there was not enough convincing evidence arising from high-quality randomized trials to suggest that


randomized clinical trial have shown that lactulose is beneficial in treating $\mathrm{HE}$ in patients with chronic liver disease. $\frac{25}{}$ Although lactulose is safe, compliance is often underachieved, given the need to titrate the dose in order to reach two or three semi-soft stools per day. In addition, lactulose treatment has been shown to cause abdominal cramping, bloating, nausea, vomiting, flatulence, and abdominal distension, the last potentially leading to technical difficulties during surgery for liver transplantation. Moreover, lactulose treatment affects intestinal absorption, and this may amplify the nutritional deficits in patients with end-stage liver disease, leading to a poorer outcome after liver transplantation. $\underline{26}$

Antibiotics. Orally administered antimicrobial agents targeting the gut have long been utilized with the primary aim of inhibiting urease-containing bacteria in the colon, thereby decreasing ammonia production and preventing absorption through the gastrointestinal tract. Antibiotics such as neomycin, metronidazole, and vancomycin have all been demonstrated to lower blood ammonia in patients with end-stage liver

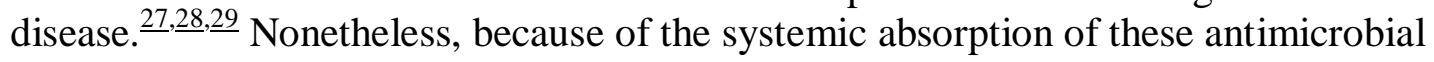
agents, serious adverse effects have been recorded, and these have limited their widespread use. Neomycin, an aminoglycoside antimicrobial, exerts its effect by binding to the $30 \mathrm{~S}$ ribosomal unit and inhibiting protein synthesis. Because neomycin is systemically absorbed ( 4\%), oral treatment potentially causes nephrotoxicity and ototoxicity. $\frac{30}{}$ Metronidazole, a nitroimidazole antimicrobial that is primarily taken up by anaerobes and causes cell toxicity, has been found to be as effective as neomycin. $\underline{28}$ However, because of its high systemic absorption, cases of neurotoxicity (peripheral

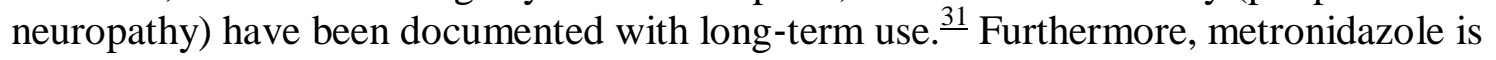
eliminated by the liver through hepatic oxidation, which adds to the risk of toxicity in patients with chronic liver disease. $\frac{32}{}$ Vancomycin, a glycopeptide antimicrobial that inhibits cell-wall synthesis in Gram-positive bacteria, has been demonstrated to lower blood ammonia and attenuate HE in patients with cirrhosis. $\frac{29}{}$ On the other hand, vancomycin treatment has also been demonstrated to lead to bacterial overgrowth and

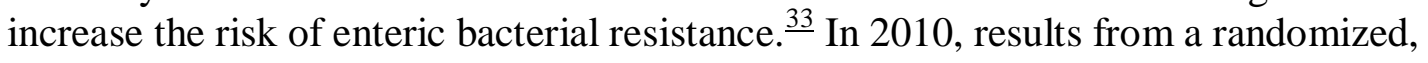
double-blind study led to the approval (in the United States) of the antibiotic rifaximin (Salix Pharmaceuticals) as reducing the risk of recurrence of overt HE in patients with end-stage liver disease..$^{34}$ Rifaximin is a semisynthetic antibiotic that is poorly absorbed $(<0.4 \%)$ because of its pyridoimidazole ring. Rifaximin binds to the $\beta$-subunit of bacterial

Rose C F. Ammonia-Lowering Strategies for the Treatment of Hepatic Encephalopathy. Clin Pharmacol Ther . 201209;92(3):321-331 
This is the peer reviewed version of the following article: Rose C F. Ammonia-Lowering Strategies for the Treatment of Hepatic Encephalopathy. Clin Pharmacol Ther . 2012-09;92(3):321-331, which has been published in final form at 10.1038/clpt.2012.112. This article may be used for non-commercial purposes in accordance with Wiley Terms and Conditions for Use of Self-Archived Versions.

DNA-dependent RNA polymerase and prevents the catalysis of polymerization of deoxyribonucleotides into a DNA strand, thereby inhibiting bacterial RNA and protein synthesis. As a result, rifaximin has a broad spectrum of antibacterial activity, including both aerobic and anaerobic and Gram-positive and Gram-negative bacteria. Rifaximin has proven to be efficient in lowering blood ammonia levels in patients with HE by

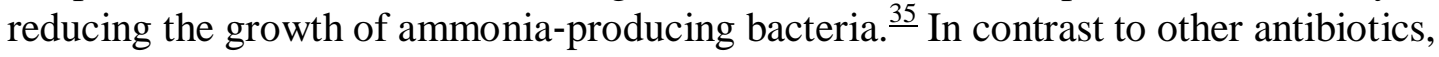
rifaximin is poorly absorbed in healthy individuals; however, its absorption in patients with severe liver disease remains to be tested. Rifaximin treatment has resulted in fewer adverse effects and a faster and greater decrease in blood ammonia in comparison with neomycin. $\frac{36}{2}$ Furthermore, higher compliance rates have been documented with rifaximin as compared with lactulose. ${ }^{37}$ Rifaximin treatment has also been shown to reduce both the frequency and duration of hospitalization, thereby lowering hospital-related costs. ${ }^{4, \underline{37}}$ All these factors make rifaximin an ideal choice for the treatment of HE, despite a higher pertreatment cost.

Probiotics. Probiotic therapy involves monocultures or mixed cultures of live microorganisms, administered orally to improve the properties of the intestinal microflora. Studies have shown that probiotics are beneficial in the treatment of HE, possibly by modulating intestinal bacteria via the colonization of non-urease bacteria and by lowering blood ammonia concentrations. $\frac{38}{}$ Moreover, probiotic supplementation in patients with HE has been shown to be very well tolerated, and the compliance rates were excellent. $\frac{39}{}$ A Cochrane review published in 2011 on the use of probiotics in patients with $\mathrm{HE}$ concluded that probiotics do reduce the concentration of plasma ammonia, but their efficacy in altering clinically relevant outcomes was inconclusive; further randomized clinical trials were suggested. $\frac{40}{}$ Moreover, some hesitation has been expressed with respect to introducing live bacteria into immunocompromised patients. An additional concern regarding probiotic treatment is that there are significant variations of the live microorganisms and a lack of standardization among probiotics manufacturers. VSL \#3 (VSL Pharmaceuticals), a combination of probiotics (bifidobacteria, lactobacilli, and a mixture of Streptococcus thermophilus strains), was proposed in 2003 as a promising probiotic therapy for HE. $\stackrel{41}{ }$ However, it has not yet been investigated in patients with HE. Efforts to identify the specific bacterial families/strains/species associated with urease activity and hyperammonemia may help advance the field of probiotic therapy in HE. $\underline{42}$

Carbon microspheres. AST-120 (Ocera Therapeutics) is an oral adsorbent that has been shown to be beneficial in patients with chronic kidney disease, $\frac{43}{}$ irritable bowel syndrome, $\underline{44}$ and active pouchitis. $\stackrel{45}{-}$ AST-120 consists of engineered activated carbon microspheres (0.2-0.4 mm in diameter) with high nonspecific adsorptive surface area $\left(>1,600 \mathrm{~m}^{2} / \mathrm{g}\right)$. These microspheres are not absorbed or degraded in the gastrointestinal tract and provide sustained binding surface for low-molecular-weight compounds $(<10$ $\mathrm{kDa}$ ) such as those present in the bowel. ${ }^{45}$ AST-120 has been shown to absorb ammonia in vitro and also to reduce hyperammonemia, attenuate brain edema, and attenuate HE in cirrhotic rats. ${ }^{46}$ In addition, AST-120 has the capacity to act as an ammonia sink by 
drawing ammonia in from the systemic circulation ${ }^{46}$ (Figure 5). This means that AST-120 absorbs not only the ammonia produced locally in the gut but also the ammonia produced by extraintestinal organs. This property makes AST-120 attractive as an ammonialowering treatment for HE. In preliminary studies, patients with low-grade HE showed significant neurocognitive improvements after AST-120 treatment. ${ }^{47}$ The efficacy, safety, and tolerability of AST-120 in the treatment of MHE were evaluated in a recent multicenter, randomized, double-blind, placebo-controlled, dose-ranging clinical trial. This study (the ASTUTE trial) was carried out in 150 patients randomized to AST-120 (6 and $12 \mathrm{~g}$ /day) or placebo for 8 weeks. AST-120 failed to attenuate MHE after 4 and 8 weeks of treatment. However, AST-120 treatment at both doses (6 and $12 \mathrm{~g} /$ day) did result in a reduction in blood ammonia levels at both 4 and 8 weeks in patients with elevated ammonia levels at baseline. Given its high ammonia-absorbing capacity (300 $\mu \mathrm{mol} / \mathrm{l} / \mathrm{g}$ ) and the high compliance rate associated with it, AST-120 thus remains a promising treatment for HE. However, a well-designed clinical trial with a longer duration of treatment is needed to prove the efficacy of AST-120 as a treatment for HE. Moreover, evaluations of the recurrence rates of HE, hospital readmissions and costs would also be important end points.

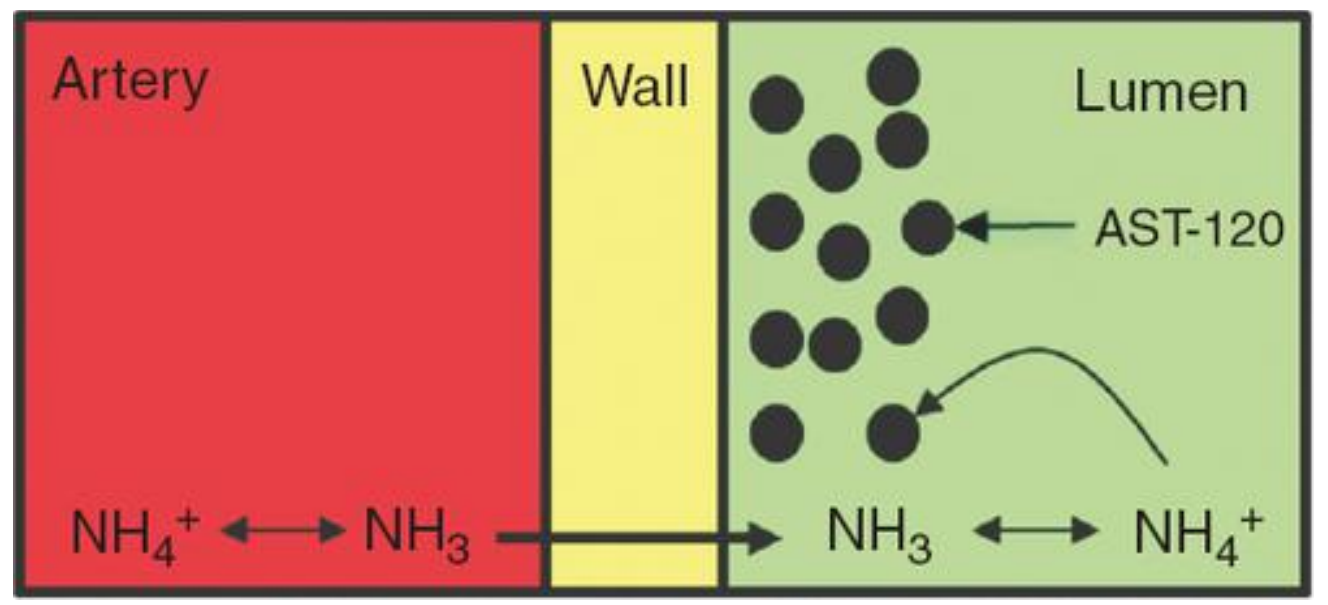

Figure 5 AST-120 as an ammonia sink. With the large capacity of AST-120 to absorb ammonia, it can also draw ammonia from blood circulation. Once absorbed by AST-120 in the lumen, ammonia will cross the intestinal wall into the lumen following its concentration gradient.

Sodium benzoate. Sodium benzoate conjugates with the amino acid glycine to form hippuric acid, which is excreted by the kidneys. Glycine is metabolized through the glycine cleavage system, an enzyme complex that consists of four proteins and generates ammonia as an end-product. Sodium benzoate is administered to prevent glycine metabolism and thereby prevent the production of ammonia. Sodium benzoate has been widely used in the therapeutic regimen to alleviate hyperammonemia in children born with urea cycle disorders. ${ }^{48}$ In the context of liver disease, a randomized, double-blind study demonstrated that sodium benzoate reduces blood ammonia levels and attenuates 
This is the peer reviewed version of the following article: Rose C F. Ammonia-Lowering Strategies for the Treatment of Hepatic Encephalopathy. Clin Pharmacol Ther . 2012-09;92(3):321-331, which has been published in final form at 10.1038/clpt.2012.112. This article may be used for non-commercial purposes in accordance with Wiley Terms and Conditions for Use of Self-Archived Versions.

the symptoms of HE as effectively as lactulose, in cirrhotic patients. $\frac{49}{}$ However, it has also been demonstrated that sodium benzoate can inhibit the production of urea, inducing hyperammonemia. The conjugation of sodium benzoate with glycine proceeds in two steps. First, benzoate and ATP (adenosine triphosphate) react with CoA (coenzyme A) to form benzoyl CoA, AMP (adenosine monophosphate), and pyrophosphate. Next, benzoyl CoA and glycine react to form hippuric acid and CoA. This second step is dependent on the concentration of glycine. Therefore, under conditions of low concentrations of glycine, benzoate-induced utilization of CoA could lead to a decrease in the activation of carbamyl phosphate synthetase I, thereby reducing urea cycle activity. This suggests that the efficacy of sodium benzoate is dependent on the level of functioning of the urea cycle, with a beneficial response occurring when the urea cycle is impaired. $\underline{50}$ However, the effectiveness of using sodium benzoate as an ammonia-lowering strategy in the context of liver disease and residual hepatocyte function remains unclear.

Sodium phenylacetate/phenylbutyrate. Sodium phenylbutyrate, which is rapidly oxidized into phenylacetate, is used to treat hyperammonemia by attenuating hyperglutaminemia in children with urea-cycle enzyme deficiencies. $\frac{51}{}$ Phenylacetate conjugates with glutamine in the liver and kidney to form phenylacetylglutamine, which is incapable of being metabolized by glutaminase, and therefore glutamine-stimulated ammoniagenesis is prevented. Phenylacetylglutamine is then excreted in the urine. The use of sodium phenylacetate/phenylbutyrate has never been investigated in the treatment of HE. This is because the degree of hyperglutaminemia seen in patients with urea-cycle enzyme deficiencies and highly functional glutamine synthetase in the perivenous hepatocytes is rarely observed in patients with end-stage liver disease or severe hepatocyte necrosis. Moreover, because the conjugation of phenylacetate is limited by the concentration of glutamine, limited availability of glutamine can lead to CoA sequestering, resulting in the inhibition of urea-cycle synthesis and hyperammonemia. In addition, the sodium load associated with the treatment, which could lead to fluid retention and exacerbate ascites, has limited its use in patients with end-stage liver disease. However, glycerol phenylbutyrate (HPN-100; Hyperion Therapeutics), a liquid triglyceride that does not contain sodium and has a favorable palatability, has recently been shown to be as effective as sodium phenylacetate. $\frac{52}{}$ It is currently being investigated as a treatment for $\mathrm{HE}$ in patients with end-stage liver disease.

Glutaminase inhibitors. The small intestine is an important source of ammonia generation, through the uptake and breakdown of glutamine by enterocytes. Phosphateactivated glutaminase is the main glutamine-catabolizing enzyme in the small intestine, and current evidence indicates that $85 \%$ of intestinal ammonia production is the result of glutaminase activity. It has been demonstrated that the duodenal glutaminase activity in cirrhotic patients is nearly fourfold higher than that in healthy controls. $\frac{53}{}$ Recently, a microsatellite (a sequence of repeated base pairs) discovered within the promoter region of the glutaminase gene was shown to be associated with the development of HE in patients with cirrhosis. $\frac{54}{4}$ Not only does this study identify a possible genetic marker for the development of HE, it also strongly suggests that glutaminase should be targeted as a

Rose C F. Ammonia-Lowering Strategies for the Treatment of Hepatic Encephalopathy. Clin Pharmacol Ther . 201209;92(3):321-331 
This is the peer reviewed version of the following article: Rose C F. Ammonia-Lowering Strategies for the Treatment of Hepatic Encephalopathy. Clin Pharmacol Ther . 2012-09;92(3):321-331, which has been published in final form at 10.1038/clpt.2012.112. This article may be used for non-commercial purposes in accordance with Wiley Terms and Conditions for Use of Self-Archived Versions.

potential ammonia-lowering strategy. Currently, specific glutaminase inhibitors do exist, such as BPTES (bis-2[5-phenylacetamido-1,2,4-thiadiazol-2-yl]ethylsulfide), THDP17, and DON (6-diazo-5-oxo-L-norleucine), but they have only been tested in vitro. The challenge is to avoid targeting and inhibiting all glutaminase activity, especially in in vivo systems, because glutaminase plays a vital role in cellular metabolism and organ function.

Acarbose. Acarbose, an approved treatment for diabetes mellitus, is an inhibitor of $\alpha$ glycosidase that primarily prevents the conversion of carbohydrates into monosaccharides. In addition, it has been demonstrated that acarbose can decrease colonic proteolytic flora and dietary nitrogenous substances. In a double-blind, crossover, randomized study, 107 cirrhotic patients with OHE and type 2 diabetes mellitus received acarbose treatment and demonstrated a significant reduction in serum ammonia levels

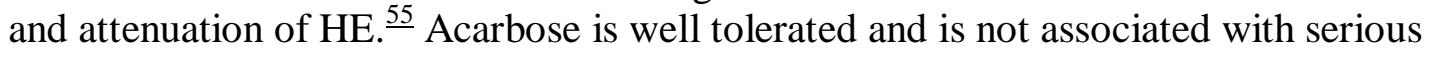
adverse effects. Additional studies are required to further evaluate the role and mechanism of action of acarbose in the treatment of HE.

INCREASING THE AMOUNT OF AMMONIA REMOVAL

Branched-chain amino acids. Treatment with branched-chain amino acids (BCAAs) has been shown to lower blood ammonia and improve the mental status of patients with endstage liver disease. $\frac{56}{}$ However, in 2004 , a Cochrane review involving a meta-analysis of 11 randomized, controlled clinical trials concluded that BCAA supplementation does not affect morbidity or mortality in patients with end-stage liver disease. $\underline{\text { }}$ Since then, a large multicenter, randomized study demonstrated that BCAA treatment reduces the risk of death and attenuates the progression of liver failure in patients with cirrhosis. $\underline{58}$ The mechanisms underlying the ammonia lowering by BCAA remain elusive. It is known that BCAAs (valine, leucine, and isoleucine) are metabolically very active. In addition, through the enzyme branched-chain aminotransferase, the amino group from the BCAA is utilized to form glutamate from $\alpha$-ketoglutarate and to detoxify ammonia through the production of glutamine via glutamine synthetase. Besides forming glutamate, BCAA metabolism, through branched-chain aminotransferase, can generate branched-chain ketoacids. These ketoacids are further metabolized into CoA compounds through branched-chain $\alpha$-ketoacid dehydrogenase before being utilized in the tricarboxylic acid cycle for oxidative energy production (Figure 6). Therefore, in addition to lowering ammonia levels through biochemical action, BCAAs can indirectly increase ammonia removal by acting as anticatabolic agents. Leucine, in particular, is capable of stimulating protein synthesis in the liver and attenuating the degradation of muscle protein. The maintenance of muscle mass is critical in patients with liver dysfunction, because the muscle is an important ammonia-removing organ, especially in the context of liver failure..$^{59}$ BCAAs are believed to be beneficial for patients with cirrhosis because they function as a nutritional supplement, reducing protein catabolism, preventing muscle wasting, and arresting progression of liver failure. This action of BCAAs would be 
expected to decrease ammonia production and improve clearance. However, a recent study showed that BCAA treatment in patients with cirrhosis resulted in an increase of blood ammonia levels. ${ }^{60}$ This study, using $\left[{ }^{13} \mathrm{~N}\right]$ ammonia positron emission tomography, concluded that BCAA metabolism in the skeletal muscle leads to an increase in glutamine production (through glutamine synthetase) from BCAA-derived ammonia rather than from blood-derived ammonia, as seen from the finding that the amount of glutamine released from the muscles was six times greater than the ammonia uptake. In this case, the glutamate derived from the BCAA reacts with the cofactor $\mathrm{NAD}^{+}$ (nicotinamide adenine dinucleotide) to form $\alpha$-ketoglutarate, and ammonia, through the enzyme glutamate dehydrogenase (Figure 6). This BCAA-induced ammonia is then removed through the formation of glutamine, released into the blood, and metabolized by glutaminase in extramuscular organs such as the kidney and intestine, ${ }^{7}$ causing a release of ammonia. Although BCAA treatment is regarded as safe, noncompliance with longterm treatment has been reported - primarily due to its poor palatability and solubility, the latter necessitating consumption of large quantities of water. Overall, BCAA treatment can be potentially beneficial as an ammonia-lowering strategy and as a treatment for HE, but to date its efficacy remains a matter of debate. A therapeutic dosing range of BCAA needs to be established for reliably lowering blood ammonia levels in cirrhotic patients with HE.

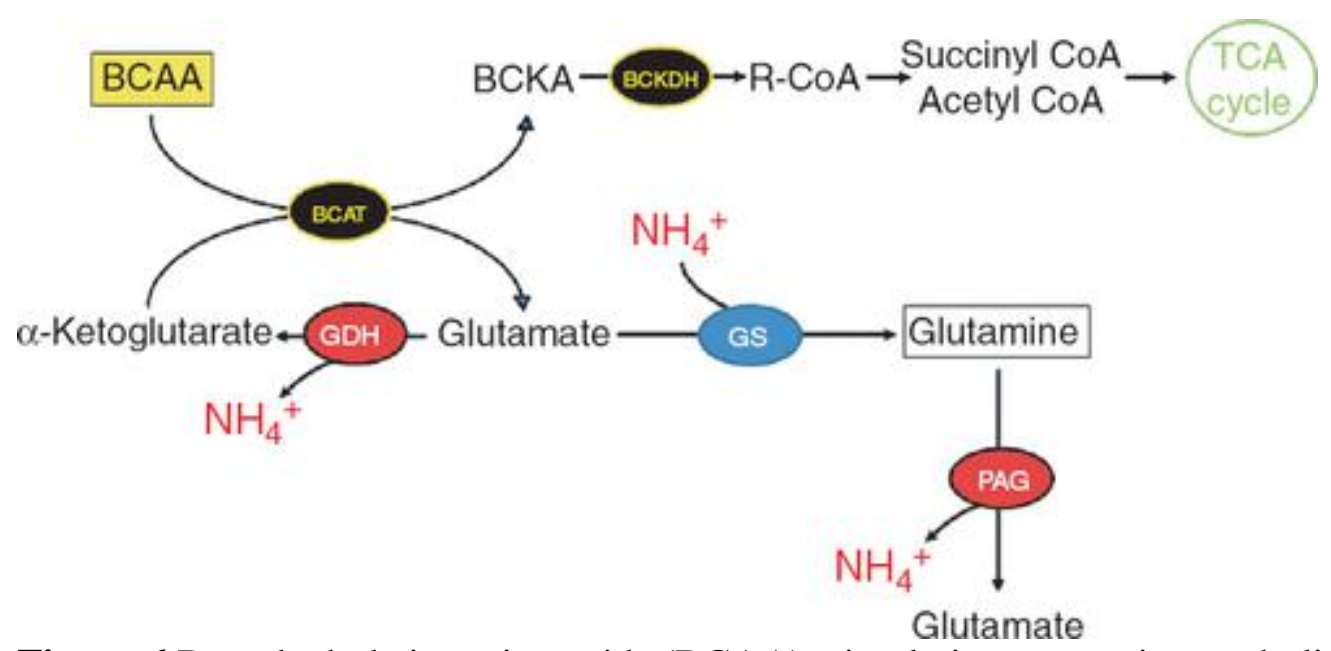

Figure 6 Branched-chain amino acids (BCAA) stimulating ammonia metabolic pathways. Valine, leucine, and isoleucine, along with $\alpha$-ketoglutarate, can be transaminated through the enzyme branched-chain amino acid transaminase (BCAT) to branched-chain ketoacids (BCKA) and glutamate. Ketoacids can be metabolized by branched-chain $\alpha$-ketoacid dehydrogenase (BCKDH) to help fuel the tricarboxylic acid (TCA) cycle. Glutamate can either be used to stimulate glutamine synthetase (GS) and remove ammonia or be metabolized by glutamate dehydrogenase (GDH) to form $\alpha$ ketoglutarate and ammonia. BCAA-derived glutamine can also form ammonia afresh through phosphate-activated glutaminase (PAG). 
This is the peer reviewed version of the following article: Rose C F. Ammonia-Lowering Strategies for the Treatment of Hepatic Encephalopathy. Clin Pharmacol Ther . 2012-09;92(3):321-331, which has been published in final form at 10.1038/clpt.2012.112. This article may be used for non-commercial purposes in accordance with Wiley Terms and Conditions for Use of Self-Archived Versions.

L-ornithine-L-aspartate. L-ornithine-L-aspartate (LOLA), both substrates of the urea cycle, were first tried as infusion treatments in patients suffering from end-stage liver disease and $\mathrm{HE}$, in an attempt to lower blood ammonia by stimulating ureagenesis in the residual hepatocytes (Figure 7a). This concept has been proven to work in ammoniainjected portacaval-shunted rats, in which LOLA infusion prevented a rise in ammonia

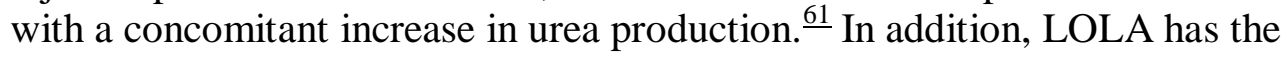
demonstrated ability to stimulate glutamine synthesis, particularly in the skeletal muscle. $\stackrel{61, \underline{62}}{ }$ L-ornithine is a substrate for ornithine aminotransferase that gives rise to glutamate and glutamate semialdehyde, which can be further metabolized through glutamate semialdehyde dehydrogenase to form another molecule of glutamate. Laspartate is also capable of generating a molecule of glutamate through aspartate- $\alpha-$ ketoglutarate transaminase. Therefore, L-ornithine and L-aspartate taken together can produce three molecules of glutamate, which in turn can fuel glutamine synthesis activity and detoxify ammonia (Figure 7b). It should also be noted that glutamate can be metabolized by glutamine dehydrogenase to form $\alpha$-ketoglutarate and ammonia. Several clinical studies have demonstrated that LOLA (administered either orally or intravenously) lowers ammonia concentrations, provides symptomatic improvement in cirrhotic patients with $\mathrm{HE}, \underline{63}$ markedly improves health-related quality of life, and is as effective as lactulose in the management of HE. In 2008, a Cochrane review, which included a meta-analysis, reported that LOLA treatment led to the attenuation of OHE; it was, however, less beneficial in patients with MHE. ${ }^{64}$ In 2009, Acharya et al. concluded, following a randomized trial of 201 patients with acute liver failure, that treatment with LOLA did not improve ammonia reduction, attenuate encephalopathy, or increase survival. $\frac{65}{}$ However, it is important to note that in this study, mortality in the placebo group was as low as $33 \%$ in comparison with an earlier study by the same group that

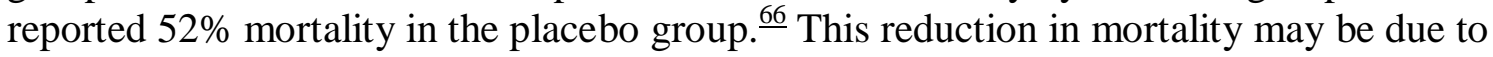
improvements in standard care, including prophylactic administration of antibiotics (piperacillin-tazobactam, fluconazole, and vancomycin). In addition, vancomycin has been shown to reduce ammonia levels in patients with cirrhosis. ${ }^{29}$ Therefore, it was conclusively shown that, in patients with acute liver failure, LOLA administration could not induce further reductions in ammonia to levels below those achieved by the standard care given to a placebo group, and that LOLA (administered at a dose of $30 \mathrm{~g} /$ day for 3 days) was not a good adjuvant to the standard care. However, very good tolerability has been documented for LOLA treatment, with no major adverse effects. The results of many studies suggest that LOLA is an efficient and promising treatment for $\mathrm{HE}$ in patients with end-stage liver disease. However, caution should be exercised in using LOLA to treat patients with acute liver failure. It appears that the duration and dosage of the LOLA treatment regimen are vital to its success and therefore need to be established. LOLA is currently not available for clinical use in North America. 



Figure 7 Possible ammonia pathways induced by L-ornithine L-aspartate. (a) L-ornithine L-aspartate, a substrate and intermediate of the urea cycle, can lower ammonia by stimulating ureagenesis. (b) L-ornithine and L-aspartate can also be transaminated with $\alpha$-ketoglutarate to glutamate, through ornithine aminotransferase (OAT) and aspartate aminotransferase (AAT), respectively. Ornithine-derived glutamate semialdehyde can be further metabolized to glutamate through glutamate semialdehyde dehydrogenase (GSDH). These three molecules of glutamate can be used to stimulate glutamine synthetase (GS), thus forming glutamine and removing ammonia. However, L-ornithine L-aspartate-derived glutamine can be metabolized through phosphate-activated glutaminase (PAG), thereby regenerating ammonia. GDH, glutamate dehydrogenase.

L-carnitine. L-carnitine, a metabolite produced by the degradation of the essential amino acid lysine, serves as a carrier for short-chain fatty acids across the mitochondrial membrane. Treatment with L-acetylcarnitine (the acetylated form of L-carnitine, known to increase its bioavailability) significantly reduced serum ammonia levels and improved mental status as compared with placebo in 150 cirrhotic patients with mild to moderate HE. $\underline{67}$ However, despite reductions in blood ammonia levels, an overall worsening per the Glasgow Coma Scale was noted in critically ill cirrhotic patients with hepatic coma who had received L-carnitine. $\underline{68}$ L-acetylcarnitine, given as pretreatment to portacaval-shunted 
This is the peer reviewed version of the following article: Rose C F. Ammonia-Lowering Strategies for the Treatment of Hepatic Encephalopathy. Clin Pharmacol Ther . 2012-09;92(3):321-331, which has been published in final form at 10.1038/clpt.2012.112. This article may be used for non-commercial purposes in accordance with Wiley Terms and Conditions for Use of Self-Archived Versions.

rats, was shown to prevent ammonia-induced encephalopathy; however, it did not provide a significant protection against an increase in blood ammonia levels after rectal administration of ammonia in subjects with cirrhosis. $\underline{69}$

Targeting a single strategy. Recently, numerous studies have been published describing various combinations of ammonia-lowering agents as treatment for $\mathrm{HE}$ in patients with cirrhosis. Some were intentionally designed to investigate the benefit of simultaneously administering two ammonia-removing agents, such as the study by Sharma et al., which investigated the beneficial effect of lactulose vs. probiotics vs. lactulose + probiotics. All three treatments were equally effective in lowering blood ammonia and in treating MHE. $\stackrel{70}{ }$ Other studies generated results of combination strategies as part of comparisons with lactulose, the standard care regimen in these studies. Recently, lactulose + rifaximin has been demonstrated to be more beneficial in preventing a recurrence of $\mathrm{HE}$ as

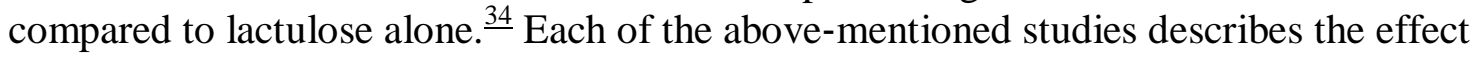
of combining two treatments, each targeting the gut, modulating the microflora, and, in effect, lowering the production of ammonia. In another study, two agents with ammoniaremoving properties (L-acetylcarnitine + BCAA) were combined. The results of this study demonstrated that L-acetylcarnitine + BCAA causes greater reduction in blood ammonia and is more beneficial in attenuating HE as compared to BCAA treatment alone. ${ }^{71}$ Sodium phenylacetate and sodium benzoate were also evaluated as a combination (Ammonul; Hyperion Therapeutics), and this regimen was approved for the treatment of hyperammonemia associated with urea-cycle disorders. ${ }^{72}$ The strategy behind combining sodium phenylacetate and sodium benzoate is that each of these agents chelates different ammoniagenic substrates. With sodium phenylacetate conjugating with glutamine, and sodium benzoate conjugating with glycine, two substrates for potential ammoniagenesis are thus removed. In the context of HE, this combination has previously been tested in a small study that suggested its possible benefit. ${ }^{73}$ It was to be tested in a clinical trial to investigate the beneficial effects of sodium phenylacetate and sodium benzoate (Ammonul; Hyperion Therapeutics) in cirrhotic patients with severe HE. However, for undisclosed reasons, the study was withdrawn prior to enrollment commenced (http://www.clinicaltrials.gov).

Overall, the idea of combining treatments targeting different ammoniaproducing/lowering systems is a valuable concept. However, selecting two agents that both inhibit ammonia production or increase ammonia removal in the same organs may be an excessive and redundant strategy.

Synergy of two strategies: L-ornithine phenylacetate. L-ornithine phenylacetate (OCR002; Ocera Therapeutics) represents a new combination treatment strategy by which, for the first time, an agent is administered in order to activate ammonia removal in combination with another agent that stimulates a reduction in ammonia production. The

Rose C F. Ammonia-Lowering Strategies for the Treatment of Hepatic Encephalopathy. Clin Pharmacol Ther . 201209;92(3):321-331 
idea of this synergistic treatment, developed by Rajiv Jalan in the United Kingdom, $\underline{74}$ is based on the fact that L-ornithine (the active component of LOLA) ${ }^{75}$ generates glutamate (through ornithine aminotransferase in muscle), thereby stimulating glutamine synthesis and reducing blood ammonia. This, in turn, leads to an increase in ornithine-derived glutamine. To prevent glutamine from being metabolized by glutaminase and forming ammonia again, phenylacetate is administered to conjugate with the ornithine-derived glutamine to form phenylacetylglutamine. Consequently, given that glutaminase is incapable of metabolizing phenylacetylglutamine, an ammonia rebound is prevented and phenylacetylglutamine is excreted by the kidneys (Figure 8). The proof of concept for the mechanism of L-ornithine phenylacetate was first tested in liver-devascularized pigs to negate the possibility of L-ornithine stimulating ureagenesis. ${ }^{10}$ In that study, L-ornithine phenylacetate treatment attenuated increases in blood and brain ammonia, brain edema, and intracranial hypertension - results that were not achieved with either L-ornithine or phenylacetate treatment alone. L-ornithine phenylacetate has also been shown to be effective in lowering blood ammonia in cirrhotic rats and portacaval-shunted rats with simulated gastrointestinal bleed. $\stackrel{9}{\underline{14}}$ To date, animal studies have demonstrated the efficacy of L-ornithine phenylacetate as an ammonia-lowering strategy. Currently, two phase II clinical trials of the safety and tolerability of L-ornithine phenylacetate treatment are under way in Spain and the United States (http://www.clinicaltrials.gov): (i) in patients with acute liver failure due to acetaminophen overdose and (ii) in patients with cirrhosis and upper gastrointestinal bleeding. This promising synergistic treatment, which combines two agents that do not target the gut, is very novel. As a therapeutic strategy, it would allow patients with cirrhosis to be properly nourished (stable protein diet) and would inhibit the development of hyperammonemia by increasing ammonia elimination.

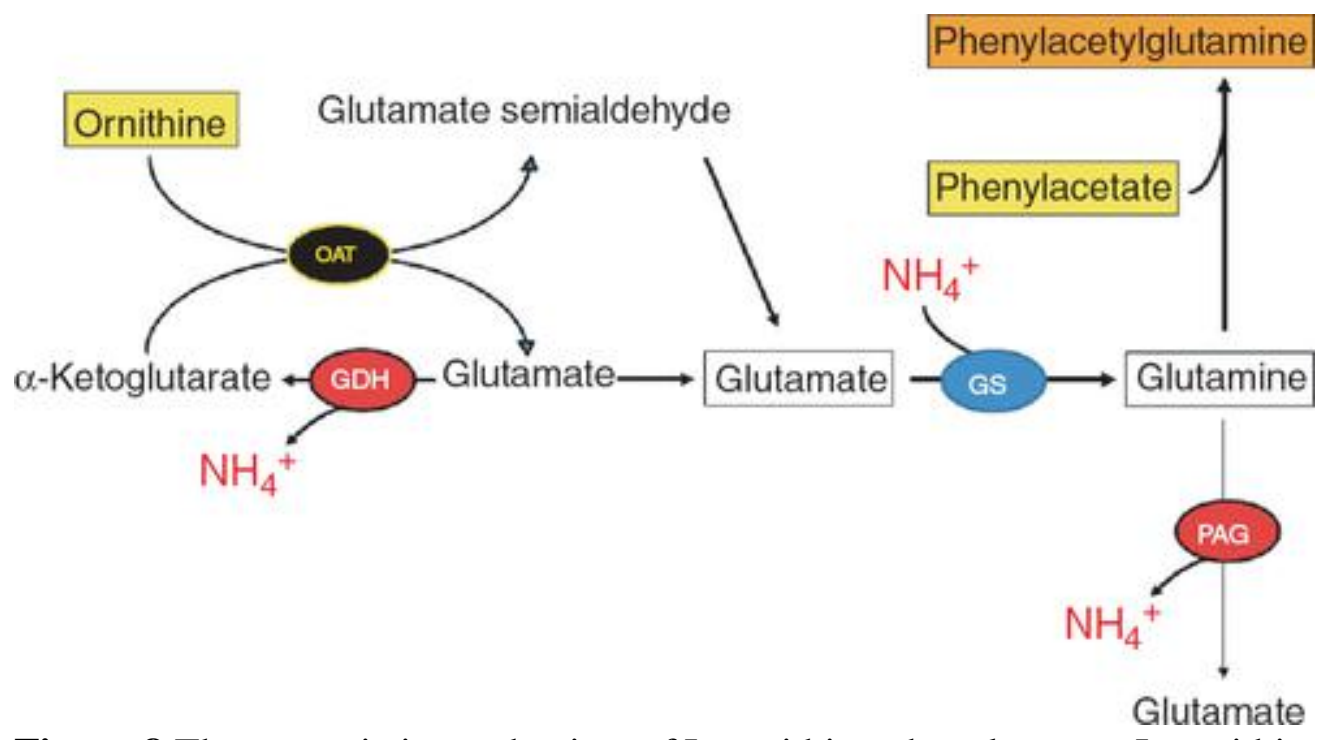

Figure 8 The synergistic mechanism of L-ornithine phenylacetate. L-ornithine (with $\alpha$ ketoglutarate) can produce two molecules of glutamate through glutamate semialdehyde dehydrogenase (GSDH) and ornithine aminotransferase (OAT) that can stimulate glutamine synthetase (GS), thereby removing ammonia and forming glutamine. To 
This is the peer reviewed version of the following article: Rose C F. Ammonia-Lowering Strategies for the Treatment of Hepatic Encephalopathy. Clin Pharmacol Ther . 2012-09;92(3):321-331, which has been published in final form at 10.1038/clpt.2012.112. This article may be used for non-commercial purposes in accordance with Wiley Terms and Conditions for Use of Self-Archived Versions.

prevent ornithine-derived glutamine from being metabolized by phosphate-activated glutaminase (PAG), phenylacetate conjugates with glutamine to form phenylacetylglutamine, which is then excreted in the urine, and thus regeneration of ammonia is prevented. GDH, glutamate dehydrogenase.

\section{SUMMARY}

$\mathrm{HE}$, a devastating neuropsychiatric syndrome, is a major complication of liver failure. Because ammonia plays such a major role in the pathogenesis of HE, ammonia-lowering strategies remain a focus for HE treatments. Historically, ammonia-lowering strategies have concentrated on inhibiting the source of ammonia production in the gut; currently, lactulose and rifaximin are the treatments of choice for HE. Other agents that inhibit ammonia production include probiotics, glutaminase inhibitors, and AST-120. However, they all need to be evaluated in high-quality clinical trials. An alternative ammonialowering strategy involves increasing ammonia removal. This focuses primarily on stimulating glutamine synthetase in the large mass capacity of skeletal muscle. BCAAs, LOLA, and L-ornithine phenylacetate have all been shown to be capable, through transamination, of generating glutamate, which stimulates glutaminase synthetase, producing glutamate and eliminating ammonia. However, under certain conditions, the $\alpha-$ ketoglutarate generated can form ammonia through glutamate dehydrogenase; also, glutamine, the ammonia-removing product, can itself be metabolized by glutaminase to produce ammonia afresh. Given that glutaminase has been described as an important enzyme associated with the risk of developing HE, glutamine would seem to be a secondary product that should be targeted for elimination. Paradoxically, however, the production of glutamine is required for the removal of ammonia. In this situation, the use of L-ornithine phenylacetate is an excellent strategy, not only to stimulate glutamine synthesis (ammonia removal) but also to prevent a glutamine-induced ammonia rebound.

Furthermore, given that malnourishment is a major concern in cirrhotic patients, targeting the gut to lower ammonia, thereby possibly altering intestinal absorption, may exacerbate malnutrition. Therefore, exploitation of ammonia-removing pathways in other organs is a potential treatment strategy; for instance, the large mass capacity of skeletal muscle renders it an attractive therapeutic target. However, sarcopenia is commonly observed in patients with cirrhosis; considered independently, it may be a result of malnutrition, which, as noted above, has a detrimental effect on outcome in terms of complications, survival after liver transplantation, and overall liver-related mortality. Therefore, to benefit from using the muscle as a therapeutic target, the detection of malnutrition is of pivotal importance. Proper nutrition that prevents loss of muscle mass in cirrhotic patients can independently lead to an increase in ammonia-removal capacity, as well as to a much better response to BCAA, LOLA, and L-ornithine phenylacetate in stimulating glutamine synthesis, with L-ornithine phenylacetate being the most beneficial in preventing glutaminase-induced ammonia rebound.

Rose C F. Ammonia-Lowering Strategies for the Treatment of Hepatic Encephalopathy. Clin Pharmacol Ther . 201209;92(3):321-331 
This is the peer reviewed version of the following article: Rose C F. Ammonia-Lowering Strategies for the Treatment of Hepatic Encephalopathy. Clin Pharmacol Ther . 2012-09;92(3):321-331, which has been published in final form at 10.1038/clpt.2012.112. This article may be used for non-commercial purposes in accordance with Wiley Terms and Conditions for Use of Self-Archived Versions.

\section{REFERENCES}

1. Stewart, C. A. \& Smith, G. E. Minimal hepatic encephalopathy. Nat Rev Gastroenterol Hepatol 4, 677-685 (2007).

2. Poordad, F. F. Review article: the burden of hepatic encephalopathy. Aliment Pharmacol Ther 25 Suppl 1, 3-9 (2007).

3. Bajaj, J. S. Review article: the modern management of hepatic encephalopathy. Aliment Pharmacol Ther 31, 537-47 (2010).

4. Neff, G. Pharmacoeconomics of Hepatic Encephalopathy. Pharmacotherapy 30, 28S-32S (2010).

5. Bosoi, C. R. \& Rose, C. F. Identifying the direct effects of ammonia on the brain. Metab Brain Dis 24, 95-102 (2009).

6. Felipo, V. \& Butterworth, R. F. Neurobiology of ammonia. Prog Neurobiol 67, 259-279 (2002).

7. Wright, G., Noiret, L., Damink, S. W. M. O. \& Jalan, R. Interorgan ammonia metabolism in liver failure: the basis of current and future therapies. Liver Int. 31, 163-75 (2011).

8. Bosoi, C. R. et al. Systemic oxidative stress is implicated in the pathogenesis of brain edema in rats with chronic liver failure. Free Radic. Biol. Med 52, 1228-1235 (2012).

9. Oria, M. et al. Ornithine phenylacetate prevents disturbances of motor-evoked potentials induced by intestinal blood in rats with portacaval anastomosis. J Hepatol 56, 109-14 (2012).

10. Ytrebø, L. M. et al. L-ornithine phenylacetate attenuates increased arterial and extracellular brain ammonia and prevents intracranial hypertension in pigs with acute liver failure. Hepatology 50, 165-174 (2009).

11. Keiding, S. et al. Brain metabolism of $13 \mathrm{~N}$-ammonia during acute hepatic encephalopathy in cirrhosis measured by positron emission tomography. Hepatology $\mathbf{4 3}$, 42-50 (2006).

12. Sørensen, M. \& Keiding, S. New findings on cerebral ammonia uptake in HE using functional (13)N-ammonia PET. Metab Brain Dis 22, 277-284 (2007).

13. Rose, C., Kresse, W. \& Kettenmann, H. Acute insult of ammonia leads to calcium-dependent glutamate release from cultured astrocytes, an effect of pH. J. Biol.

Chem. 280, 20937-20944 (2005).

14. Davies, N. A. et al. L-ornithine and phenylacetate synergistically produce sustained reduction in ammonia and brain water in cirrhotic rats. Hepatology 50, 155-164 (2009).

15. Rovira, A., Alonso, J. \& Córdoba, J. MR imaging findings in hepatic encephalopathy. AJNR Am J Neuroradiol 29, 1612-1621 (2008).

16. Chatauret, N., Zwingmann, C., Rose, C., Leibfritz, D. \& Butterworth, R. F. Effects of hypothermia on brain glucose metabolism in acute liver failure: a H/C-nuclear magnetic resonance study. Gastroenterology 125, 815-824 (2003).

17. Schiano, T. Complications of chronic liver disease. Current Diagnosis and Treatment in Gastroenterology (2002). 
This is the peer reviewed version of the following article: Rose C F. Ammonia-Lowering Strategies for the Treatment of Hepatic Encephalopathy. Clin Pharmacol Ther . 2012-09;92(3):321-331, which has been published in final form at 10.1038/clpt.2012.112. This article may be used for non-commercial purposes in accordance with Wiley Terms and Conditions for Use of Self-Archived Versions.

18. Kundra, A., Jain, A., Banga, A., Bajaj, G. \& Kar, P. Evaluation of plasma ammonia levels in patients with acute liver failure and chronic liver disease and its correlation with the severity of hepatic encephalopathy and clinical features of raised intracranial tension. Clin Biochem 38, 696-699 (2005).

19. Shawcross, D. L., Davies, N. A., Williams, R. \& Jalan, R. Systemic inflammatory response exacerbates the neuropsychological effects of induced hyperammonemia in cirrhosis. J Hepatol 40, 247-254 (2004).

20. Montoliu, C. et al. 3-Nitro-Tyrosine as a Peripheral Biomarker of Minimal Hepatic Encephalopathy in Patients With Liver Cirrhosis. Am J Gastroenterol 106, 16291637 (2011).

21. Bémeur, C., Desjardins, P. \& Butterworth, R. F. Role of nutrition in the management of hepatic encephalopathy in end-stage liver failure. J Nutr Metab 2010, 489823 (2010).

22. van Leeuwen, P. A., van Berlo, C. L. \& Soeters, P. B. New mode of action for lactulose. Lancet 1, 55-56 (1988).

23. Sharma, P., Agrawal, A., Sharma, B. C. \& Sarin, S. K. Prophylaxis of hepatic encephalopathy in acute variceal bleed: a randomized controlled trial of lactulose versus no lactulose. J. Gastroenterol. Hepatol. 26, 996-1003 (2011).

24. Als-Nielsen, B., Gluud, L. L. \& Gluud, C. Non-absorbable disaccharides for hepatic encephalopathy: systematic review of randomised trials. BMJ 328, 1046 (2004).

25. Prasad, S. et al. Lactulose improves cognitive functions and health-related quality of life in patients with cirrhosis who have minimal hepatic encephalopathy. Hepatology 45, 549-559 (2007).

26. Teperman, L. W. \& Peyregne, V. P. Considerations on the impact of hepatic encephalopathy treatments in the pretransplant setting. Transplantation 89, 771-8 (2010).

27. Conn, H. O. et al. Comparison of lactulose and neomycin in the treatment of chronic portal-systemic encephalopathy. A double blind controlled trial.

Gastroenterology 72, 573-583 (1977).

28. Morgan, M. H., Read, A. E. \& Speller, D. C. Treatment of hepatic encephalopathy with metronidazole. Gut 23, 1-7 (1982).

29. Tarao, K. et al. Successful use of vancomycin hydrochloride in the treatment of lactulose resistant chronic hepatic encephalopathy. Gut 31, $702-706$ (1990).

30. Greenberg, L. H. \& Momary, H. Audiotoxicity and nephrotoxicity due to orally administered neomycin. JAMA 194, 827-828 (1965).

31. Heaney, C. J., Campeau, N. G. \& Lindell, E. P. MR imaging and diffusionweighted imaging changes in metronidazole (Flagyl)-induced cerebellar toxicity. AJNR Am J Neuroradiol 24, 1615-1617 (2003).

32. Loft, S., Sonne, J., Døssing, M. \& Andreasen, P. B. Metronidazole pharmacokinetics in patients with hepatic encephalopathy. Scand. J. Gastroenterol. 22, 117-123 (1987).

33. Smith, T. L. et al. Emergence of vancomycin resistance in Staphylococcus aureus. Glycopeptide-Intermediate Staphylococcus aureus Working Group. N. Engl. J. Med. 340, 493-501 (1999).

34. Bass, N. M. et al. Rifaximin treatment in hepatic encephalopathy. N. Engl. J. Med.

Rose C F. Ammonia-Lowering Strategies for the Treatment of Hepatic Encephalopathy. Clin Pharmacol Ther . 201209;92(3):321-331 
This is the peer reviewed version of the following article: Rose C F. Ammonia-Lowering Strategies for the Treatment of Hepatic Encephalopathy. Clin Pharmacol Ther . 2012-09;92(3):321-331, which has been published in final form at 10.1038/clpt.2012.112. This article may be used for non-commercial purposes in accordance with Wiley Terms and Conditions for Use of Self-Archived Versions.

362, 1071-81 (2010).

35. Mas, A. et al. Comparison of rifaximin and lactitol in the treatment of acute hepatic encephalopathy: results of a randomized, double-blind, double-dummy, controlled clinical trial. J. Hepatol. 38, 51-58 (2003).

36. Pedretti, G., Calzetti, C., Missale, G. \& Fiaccadori, F. Rifaximin versus neomycin on hyperammoniemia in chronic portal systemic encephalopathy of cirrhotics. A doubleblind, randomized trial. Ital J Gastroenterol 23, 175-178 (1991).

37. Leevy, C. B. \& Phillips, J. A. Hospitalizations during the use of rifaximin versus lactulose for the treatment of hepatic encephalopathy. Dig. Dis. Sci. 52, 737-741 (2007). 38. Malaguarnera, M. et al. Bifidobacterium longum with fructo-oligosaccharide (FOS) treatment in minimal hepatic encephalopathy: a randomized, double-blind, placebo-controlled study. Dig. Dis. Sci. 52, 3259-3265 (2007).

39. Bajaj, J. S. et al. Probiotic Yogurt for the Treatment of Minimal Hepatic Encephalopathy. Am J Gastroenterol 103, 1707-1715 (2008).

40. McGee, R. G., Bakens, A., Wiley, K., Riordan, S. M. \& Webster, A. C. Probiotics for patients with hepatic encephalopathy. Cochrane Database Syst Rev CD008716 (2011).doi:10.1002/14651858.CD008716.pub2

41. Solga, S. F. Probiotics can treat hepatic encephalopathy. Med. Hypotheses 61, 307-313 (2003).

42. Bajaj, J. S. et al. Linkage of gut microbiome with cognition in hepatic encephalopathy. Am. J. Physiol. Gastrointest. Liver Physiol. 302, G168-175 (2012). 43. Hatakeyama, S. et al. Effect of an Oral Adsorbent, AST-120, on Dialysis Initiation and Survival in Patients with Chronic Kidney Disease. Int J Nephrol 2012, 376128 (2012).

44. Tack, J. F., Miner, P. B., Jr, Fischer, L. \& Harris, M. S. Randomised clinical trial: the safety and efficacy of AST-120 in non-constipating irritable bowel syndrome - a double-blind, placebo-controlled study. Aliment. Pharmacol. Ther. 34, 868-877 (2011).

45. Shen, B. et al. The efficacy and tolerability of AST-120 (spherical carbon adsorbent) in active pouchitis. Am. J. Gastroenterol. 104, 1468-1474 (2009).

46. Bosoi, C. R., Parent-Robitaille, C., Anderson, K., Tremblay, M. \& Rose, C. F. AST-120 (spherical carbon adsorbent) lowers ammonia levels and attenuates brain edema in bile-duct ligated rats. Hepatology 53, 1995-2002 (2011).

47. Pockros, P. et al. Phase 2, Multicenter, Randomized Study of AST-120 (spherical Carbon Adsorbent) Vs. Lactulose in the Treatment of Low-Grade Hepatic Encephalopathy. J Hepatol. 50, S43-44 (2009).

48. Batshaw, M. L. et al. Treatment of inborn errors of urea synthesis: activation of alternative pathways of waste nitrogen synthesis and excretion. N. Engl. J. Med. 306, 1387-1392 (1982).

49. Sushma, S. et al. Sodium benzoate in the treatment of acute hepatic encephalopathy: a double-blind randomized trial. Hepatology 16, 138-144 (1992).

50. Maswoswe, S. M. \& Tremblay, G. C. Biosynthesis of hippurate, urea and pyrimidines in the fatty liver: studies with rats fed orotic acid or a diet deficient in choline and inositol, and with genetically obese (Zucker) rats. J. Nutr. 119, 273-279 (1989). 51. Honda, S. et al. Successful treatment of severe hyperammonemia using sodium

Rose C F. Ammonia-Lowering Strategies for the Treatment of Hepatic Encephalopathy. Clin Pharmacol Ther . 201209;92(3):321-331 
This is the peer reviewed version of the following article: Rose C F. Ammonia-Lowering Strategies for the Treatment of Hepatic Encephalopathy. Clin Pharmacol Ther . 2012-09;92(3):321-331, which has been published in final form at 10.1038/clpt.2012.112. This article may be used for non-commercial purposes in accordance with Wiley Terms and Conditions for Use of Self-Archived Versions.

phenylacetate powder prepared in hospital pharmacy. Biol. Pharm. Bull. 25, 1244-1246 (2002).

52. Lichter-Konecki, U. et al. Ammonia control in children with urea cycle disorders (UCDs); phase 2 comparison of sodium phenylbutyrate and glycerol phenylbutyrate. Mol. Genet. Metab. 103, 323-329 (2011).

53. Romero-Gómez, M., Jover, M., Galán, J. J. \& Ruiz, A. Gut ammonia production and its modulation. Metab Brain Dis 24, 147-57 (2009).

54. Romero-Gómez, M. et al. Variations in the promoter region of the glutaminase gene and the development of hepatic encephalopathy in patients with cirrhosis: a cohort study. Ann. Intern. Med. 153, 281-8 (2010).

55. Gentile, S. et al. A randomized controlled trial of acarbose in hepatic encephalopathy. Clin. Gastroenterol. Hepatol. 3, 184-191 (2005).

56. Marchesini, G. et al. Long-term oral branched-chain amino acid treatment in chronic hepatic encephalopathy. A randomized double-blind casein-controlled trial. The Italian Multicenter Study Group. J. Hepatol. 11, 92-101 (1990).

57. Als-Nielsen, B., Koretz, R. L., Kjaergard, L. L. \& Gluud, C. Branched-chain amino acids for hepatic encephalopathy. Cochrane Database Syst Rev CD001939 (2003).doi:10.1002/14651858.CD001939

58. Marchesini, G. et al. Nutritional supplementation with branched-chain amino acids in advanced cirrhosis: a double-blind, randomized trial. Gastroenterology 124, 1792-1801 (2003).

59. Chatauret, N. et al. Direct molecular and spectroscopic evidence for increased ammonia removal capacity of skeletal muscle in acute liver failure. J. Hepatol. 44, 10831088 (2006).

60. Dam, G. et al. Branched-chain amino acids increase arterial blood ammonia in spite of enhanced intrinsic muscle ammonia metabolism in patients with cirrhosis and healthy subjects. Am. J. Physiol. Gastrointest. Liver Physiol. 301, G269-277 (2011).

61. Rose, C. et al. L-ornithine-L-aspartate in experimental portal-systemic encephalopathy: therapeutic efficacy and mechanism of action. Metab Brain Dis 13, 147157 (1998).

62. Rose, C. et al. L-ornithine-L-aspartate lowers plasma and cerebrospinal fluid ammonia and prevents brain edema in rats with acute liver failure. Hepatology 30, 636640 (1999).

63. Kircheis, G. et al. Therapeutic efficacy of L-ornithine-L-aspartate infusions in patients with cirrhosis and hepatic encephalopathy: results of a placebo-controlled, double-blind study. Hepatology 25, 1351-1360 (1997).

64. Jiang, Q., Jiang, X.-H., Zheng, M.-H. \& Chen, Y.-P. L-Ornithine-1-aspartate in the management of hepatic encephalopathy: a meta-analysis. J. Gastroenterol. Hepatol. 24, 9-14 (2009).

65. Acharya, S. K., Bhatia, V., Sreenivas, V., Khanal, S. \& Panda, S. K. Efficacy of L-ornithine L-aspartate in acute liver failure: a double-blind, randomized, placebocontrolled study. Gastroenterology 136, 2159-2168 (2009).

66. Bhatia, V., Singh, R. \& Acharya, S. K. Predictive value of arterial ammonia for complications and outcome in acute liver failure. Gut 55, 98-104 (2006).

Rose C F. Ammonia-Lowering Strategies for the Treatment of Hepatic Encephalopathy. Clin Pharmacol Ther . 201209;92(3):321-331 
67. Malaguarnera, M. et al. Effects of L-carnitine in patients with hepatic encephalopathy. World J. Gastroenterol. 11, 7197-7202 (2005).

68. Malaguarnera, M. et al. Effects of L-acetylcarnitine on cirrhotic patients with hepatic coma: randomized double-blind, placebo-controlled trial. Dig. Dis. Sci. 51, 22422247 (2006).

69. del Olmo, J. A. et al. Effect of L-carnitine upon ammonia tolerance test in cirrhotic patients. Adv. Exp. Med. Biol. 272, 197-208 (1990).

70. Sharma, P., Sharma, B. C., Puri, V. \& Sarin, S. K. An open-label randomized controlled trial of lactulose and probiotics in the treatment of minimal hepatic encephalopathy. Eur J Gastroenterol Hepatol 20, 506-511 (2008).

71. Malaguarnera, M. et al. Branched chain amino acids supplemented with Lacetylcarnitine versus BCAA treatment in hepatic coma: a randomized and controlled double blind study. Eur J Gastroenterol Hepatol 21, 762-770 (2009).

72. Enns, G. M. et al. Survival after treatment with phenylacetate and benzoate for urea-cycle disorders. N. Engl. J. Med. 356, 2282-2292 (2007).

73. Mendenhall, C. L., Rouster, S., Marshall, L. \& Weesner, R. A new therapy for portal systemic encephalopathy. Am. J. Gastroenterol. 81, 540-543 (1986).

74. Jalan, R., Wright, G., Davies, N. A. \& Hodges, S. J. L-Ornithine phenylacetate (OP): a novel treatment for hyperammonemia and hepatic encephalopathy. Med. Hypotheses 69, 1064-1069 (2007).

75. Zieve, L., Lyftogt, C. \& Raphael, D. Ammonia toxicity: comparative protective effect of various arginine and ornithine derivatives, aspartate, benzoate, and carbamyl glutamate. Metab Brain Dis 1, 25-35 (1986). 